\section{"Too Many Cooks Spoil the Broth": The More Antigens Present, the Easier, the Quicker, and the More Severe the Anaphylaxis}

Kounis $\mathrm{NG}^{1}$, Koniari $\mathrm{I}^{2}$, Velissaris $\mathrm{D}^{3}$, Plotas $\mathrm{P}^{4}$, Tsigkas $\mathrm{G}^{1}$, Soufras GD 5 , Chourdakis E ${ }^{6}$, Davlouros $\mathrm{P}^{1}$, Hahalis $\mathrm{G}^{1}$

${ }^{\prime}$ Department of Cardiology, University of Patras Medical School, Rion, Patras, Achaia, Greece

${ }^{2}$ Electrophysiology and Device Department, University Hospital of South Manchester NHS Foundation Trust, Manchester, UK

${ }^{3}$ Department of Internal Medicine, University Hospital of Patras, Patras, Greece

${ }^{4}$ Department of Ophthalmology, Medical School, University of Patras, Patras, Greece

'Department of Cardiology, "Saint Andrews" State General Hospital, Patras, Achaia, Greece

${ }^{6}$ Krankenhaus der Barmherzigen Brüder, Trier, Germany

J Investig Allergol Clin Immunol 2019; Vol. 29(4): 333-334 doi: 10.18176/jiaci.0389

Key words: Allergy. Anaphylaxis. Anaphylactic shock. Kounis syndrome. Skin tests.

Palabras clave: Alergia. Anafilaxia. Shock anafiláctico. Síndrome de Kounis. Pruebas cutáneas.

\section{Dear Editor:}

We read with interest the important report published in the Journal of Investigational Allergology and Clinical Immunology [1] concerning a 62-year-old woman who experienced an anaphylactic reaction during cataract surgery after intravenous administration of cefuroxime and methylprednisolone. The patient had been receiving 9 different medications before surgery. While not atopic, she had alcoholism, idiopathic hypertension, dyslipidemia, chronic obstructive pulmonary disease, and osteoporosis. One month later, while undergoing a skin prick test with cephalosporins, which was strongly positive for cefuroxime, the patient began to experience severe dyspnea, oropharyngeal tightness, severe bronchospasm, cyanosis, loss of consciousness, and acute elevation of serum tryptase levels with absence of skin manifestations. She was treated with intense antiallergic therapy and respiratory life support.

This report raises major issues concerning the risks of skin prick testing, the use of polypharmacy, and anaphylaxis without skin manifestations.

1. The frequency of allergic, hypersensitivity, or anaphylactic reactions in patients with a high likelihood of allergy after skin testing is as high as $10 \%$ [2]. The authors stated that their case was the only case in the English-language literature of a severe systemic reaction induced by skin prick testing with a cephalosporin. However, we previously reported a case of anaphylaxisassociated acute coronary Kounis syndrome following skin tests (prick tests and intradermal tests) with amoxicillin [3]. The patient in question was a 71-year-old hypertensive man with a history of physical discomfort, vomiting, and generalized hives within minutes of taking an amoxicillin tablet 3 years previously. Approximately 10 minutes after the intradermal tests with amoxicillin, the findings recorded were a papule $(9 \times 8 \mathrm{~mm})$, physical discomfort, generalized itching, dizziness, hypotension, bowel incontinence, and oppression of the epigastrium. Electrocardiographic changes were recorded in the anterolateral leads, with elevation of troponin and serum tryptase. The specific IgE determinations against ß-lactams (penicillin $\mathrm{G}$, penicillin $\mathrm{V}$, amoxicillin, and ampicillin) that were carried out 2 weeks later yielded positive results $(0.35 \mathrm{kU} / \mathrm{L})$ to amoxicillin only.

2. Mast cells and basophils carry surface receptors for immunoglobulin E (IgE) antibodies. When allergens such as drugs, metal anions, polymers, latex, disinfectants, and infusion materials bridge their corresponding receptor bound IgE antibodies, then mast cells and basophils degranulate and release their inflammatory mediators. Such degranulation takes place when the bridged IgE antibodies reach the critical number of 2000, making 1000 bridges from a maximal number of some 500000 to $1000000 \mathrm{IgE}$ antibodies on the cell surface [4].

Theoharides and Kalogeromitros [5] found that mast cells can be activated by nonallergic triggers, often without degranulation, but with selective release of potent and vasoactive compounds. IgE antibodies with different specificities can have additive effects and small, even subthreshold numbers can join forces and trigger the cells to release their mediators. This can happen when the patient is simultaneously exposed to the corresponding antigens [6]. However, clinical studies indicate that atopic patients simultaneously exposed to several allergens have more symptoms than monosensitized individuals [7]

In the case reported by Fernandes et al [1], the patient was receiving 9 different medications as her standard treatment, namely, enalapril/lercanidipine, rosuvastatin, mirtazapine, oxazepam, acetylsalicylic acid, inhaled budesonide, tiotropium bromide, and indacaterol. Therefore, she was exposed to 11 different drugs, most of which have been thought to induce allergic reactions, albeit rarely [8]. Nevertheless, as the patient was tested and found to be allergic to cefuroxime, we assume that such simultaneous exposure to many substances could 
have been an additional etiological factor for the ensuing severe anaphylaxis.

3. The patient reported developed severe anaphylaxis without skin manifestations that could have rendered the diagnosis of anaphylaxis difficult [9]. However, there are reports of severe anaphylaxis without skin involvement, and this has been attributed to shock due to reduced cardiac output from leakage of plasma and volume loss that reduces venous return and prevents or delays the released anaphylactic mediators from reaching and acting on the skin, thus inducing redness, rash, and/ or itching [10].

Physicians should always remember that drugs used with minimally invasive techniques, such as skin prick tests, could join forces with multiple concurrent medications and induce atypical but severe anaphylactic reactions with cardiovascular collapse. Therefore, Aristotle's (384-322 B.C.) dictum "Not many is the good, but in the good, the many" should always be borne in mind.

\section{Funding}

The authors declare that no funding was received for the present study.

\section{Conflicts of Interest}

The authors declare that they have no conflicts of interest.

\section{References}

1. Fernandes RA, Regateiro FS, Pita J, Ribeiro C, Carrapatoso I, Todo-Bom A, et al.Severe Anaphylaxis With Cardiac Arrest Caused by Prick Test With Cefuroxime. J Investig Allergol Clin Immunol.2018;28:426-8.

2. Antico A, Pagani M, Compalati E, Vescovi PP, Passalacqua G. Risk assessment of immediate systemic reactions from skin tests with $\beta$-lactam antibiotics. Int Arch Allergy Immunol. 2011;156:427-33.

3. González-de-Olano D, Gandolfo-Cano M, Mohedano-Vicente E, González-Mancebo E, Matito A, Kounis NG, et al. Kounis syndrome following the performance of skin test to amoxicillin. Int J Cardiol.2014;174:856-7

4. Wickman M. When allergies complicate allergies Allergy.2005;60:1-8.

5. Theoharides TC, Kalogeromitros D. The critical role of mast cells in allergy and inflammation. Ann N Y Acad Sci.2006;1088:7899.

6. Nopp A, Johansson SG, Lundberg M, Oman H. Simultaneous exposure of several allergens has an additive effect on multisensitized basophils. Allergy.2006;61:1366-8.

7. MacGlashan DW Jr, Brochner BS, Adelman DC, Jardieu PM, Togias A, Mckenzie-White J, et al. Down-regulation of $\mathrm{F} c \varepsilon \mathrm{RI}$ expression in human basophils during in vivo treatment of atopic patients with anti-IgE antibody. J Immunol.1997;158:1438-45

8. Despotopoulos S, Roumeliotis A, Kounis NG, Tsigkas G, Hahalis G, Davlouros P. Severe allergic reaction during angioplasty culminating to fatal acute stent thrombosis: An association with Kounis syndrome. Heart Lung. 2018 Sep 21. pii: S01479563(18)30197-3.

9. Adachi $H$, Ihara $M$, Nojima $Y$, Kurimoto $T$, Nanto S.Kounis syndrome caused by anaphylaxis without skin manifestations after cefazolin administration. J Allergy Clin Immunol Pract. 2019;7:317-9.

10. Kounis NG, Cervellin G, Koniari I, Bonfanti L, Dousdampanis P, Charokopos N, et al. Anaphylactic cardiovascular collapse and Kounis syndrome: systemic vasodilation or coronary vasoconstriction? Ann Transl Med. 2018;6:332.

Manuscript received February 17, 2019; accepted for publication March 6, 2019.

\section{Nicholas G Kounis}

Department of Cardiology

University of Patras Medical School, Rion

7 Aratou Street, Queen Olgas Square

Patras 26221, Greece,

E-mail: ngkounis@otenet.gr 